The Geneva Papers on Risk and Insurance, 22 (No. 82, January 1997) 3-16

\title{
Insurance Derivatives and Securitization : New Hedging Perspectives for the US Cat Insurance Market
}

\author{
by Walter Kielholz* and Alex Durrer**
}

\section{Introduction}

Never before have natural catastrophes worldwide caused such high losses as in the 1990s. The American property/casualty insurance industry has been hardest hit due to an accumulation of the most expensive catastrophe events in the USA. ${ }^{1}$ Even more crucial than the tremendous record highs is the fact that in the long-term comparison, not only the frequency of natural catastrophes but also the average loss per event has increased massively for the insurance industry. This can partly be attributed to population growth and the subsequent concentration of value in disaster-prone regions.

The largest US catastrophe risks include earthquakes in California and hurricanes in Florida. Computer simulation models run by specialists quantify probable maximum losses for these reference events, which could cost the insurance industry between USD 50 and over 100 billion, depending on the scenario. These cumulative potential losses are currently matched by stated capital and surplus of the entire US property/casualty insurance industry to the amount of USD 200 billion. About USD 20 billion of this belongs to the US reinsurers. However, the capital and surplus of the insurance industry must also be available for a variety of other obligations, e.g. for the consequences of aggravated American product liability. As a result, the traditional insurance system currently faces a significant capacity gap in the area of natural catastrophe risks.

In contrast, the capitalization of the international financial markets seems impressive (see figure 1). Wealth invested in the USA alone amounts to about USD 19 trillion, and its daily fluctuation - about 70 basis points or USD 133 billion on average - exceeds the maximum possible insurance loss which might arise from an earthquake catastrophe.

* As a member of the Executive Board Walter Kielholz was responsible for the Alternative Risk Transfer Markets and since 1.1.1997 he is Chief Executive Officer of Swiss Re Group.

** Alex Durrer is a Senior Economist at Swiss Re Economic Research, Zurich.

1 The record list of the most expensive insurance losses in the past 25 years is topped by far by Hurricane "Andrew" (USD 16 billion) and the Northridge Earthquake in Southern California (USD 12 billion); see Swiss Re, Sigma no. 2/1996. Appendix 2. 
Figure 1: Insured US cat losses versus capitalization of the US insurance industry and the US financial markets

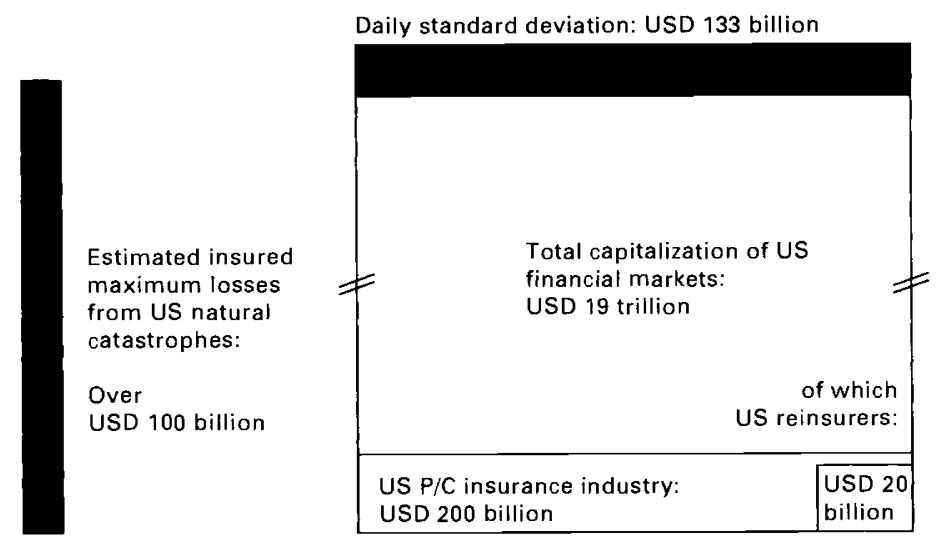

Against this backdrop, the search for new capacity has led to the prospect of not only trading insurance risks within the traditional insurance and reinsurance markets (as has hitherto been the case) but also transferring them to the much more liquid financial markets. ${ }^{2}$ The first attempt to do this was made by the Chicago Board of Trade (CBOT) which has been trading futures on catastrophe loss indices and related options since the end of 1992. In addition to these standardised index products, which have already been refined and improved in many respects following initial difficulties, securitization models for private placements are being developed and offered today in various areas. This enables investors - primarily large institutional investors are targeted at present - to directly participate ("over the counter") in certain catastrophe risks, e.g. by buying bonds whose interest or principal payments depend on the respective loss pattern.

The trend displays certain parallels to the securitization process in the banking sector (see figure 2). When the worldwide debt crisis at the start of the 1980 s led to capacity constraints in the commercial lending area, traditional corporate financing was increasingly complemented and partly substituted through the direct issuance of securities via the capital markets.

In the following we analyse the innovation process in the area of insurance derivatives and securitization, and how a new link is emerging between the insurance industry and the financial markets. Our article is supposed to illuminate the background issues and to describe alternative risk transfer mechanisms within the context of natural catastrophe problems in the USA. A discussion of start-up difficulties and an estimation of the development potential follow from both an insurance and an investment perspective.

2 The impressive capitalization of the financial markets and their ability to absorb large shocks without system breakdowns is a necessary condition for mastering major losses from natural catastrophes. As outlined in the following sections, these characteristics alone certainly do not form a sufficient basis for solving the catastrophe problem. 
Figure 2: Securitization parallels between banking and insurance

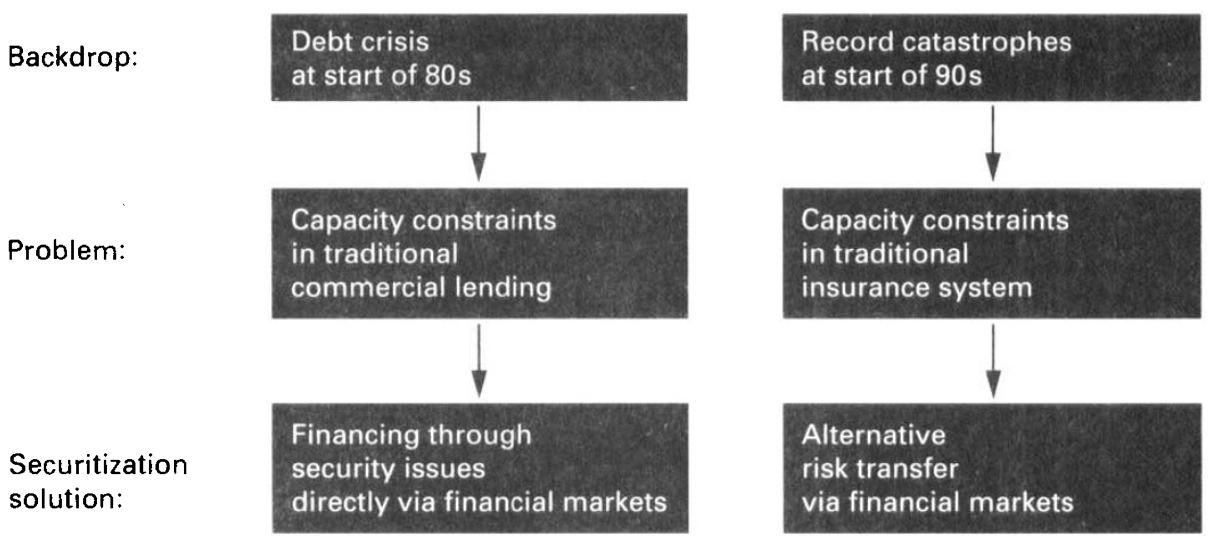

\section{The traditional cat reinsurance market in the USA : an overview for 1995}

With premiums in excess of USD 1.5 billion or more than $40 \%$, the USA held the largest share of the world market for non-proportional catastrophe reinsurance in 1995 . The US market also clearly dominates regarding total volume of cover, posting around USD 17 billion. Yet these key figures can only be interpreted meaningfully when viewed in relation to the potential insurance losses, particularly since need for cover is substantially higher in the United States, due to the country's enormous natural catastrophe potential, than in all other regions of the world.

Figure 3: US cat covers: insufficient both in storm-prone and earthquake-exposed regions

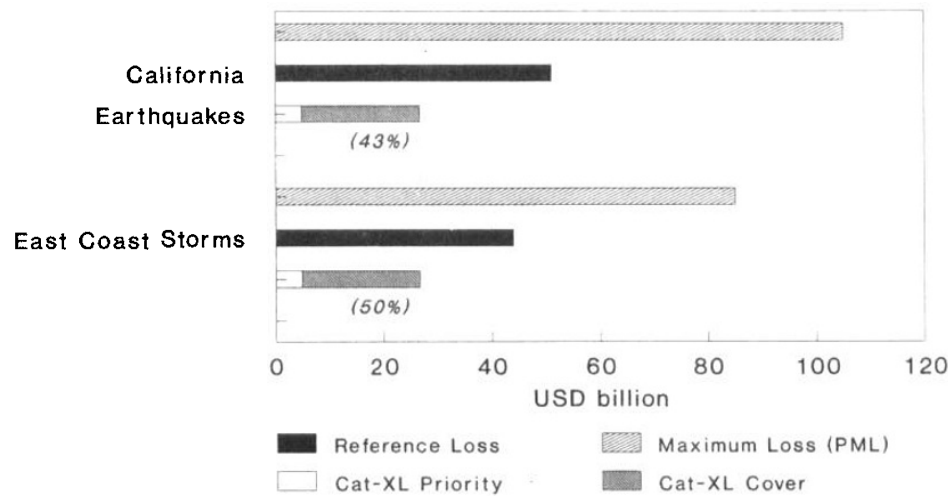

Data for 1995; Source: sigma no. 6/95 
Figure 3 provides such a comparison. It compares the aggregated CatXL cover for the largest US catastrophe risks respectively with a so-called "reference loss" 3 as well as with a probable maximum loss (PML) estimated by experts for the property/casualty insurance industry. Based on the reference losses, which are far below the PML estimates, a cover gap of between USD 20 and 30 billion is apparent. In the event of a California earthquake entailing total losses of USD 50 billion, the primary insurers would have to pay for more than half of the loss burden. ${ }^{4}$

This rough examination of the discrepancy however does not include any of the price aspects. On one hand, both the supply of and demand for traditional catastrophe reinsurance protection depend on a number of other factors in addition to the premium rate (the "rate on line"), including the capital resources of the insurers and reinsurers as well as their risk tolerance. On the other hand, technical shortcomings stand in the way of economic modelling by means of classical supply and demand curves: namely, the fact that the individual layers of a CatXL program do not represent standardisable or homogeneous capacity (due to their different probability of being hit in case of a loss). ${ }^{5}$ Despite this difficulty, when we look at the development scenarios, we will return to the question of price effects which could cause a substantial influx of alternative capacity into the traditional catastrophe reinsurance market.

\section{Alternative risk transfer mechanisms (existing and emerging)}

\subsection{The Chicago Board of Trade's "PCS cat insurance options"}

Three and a half years have already gone by since the launch of the first generation of derivative reinsurance products: The CBOT began trading in futures on catastrophe loss indices and related options at the end of 1992. Due to various technical problems which led to very thin trading volumes, the product range of these standardised hedging instruments has been refined and expanded in many respects since then. ${ }^{6}$

The current option contracts trade based on nine catastrophe loss indices which are calculated and provided daily by "Property Claims Services" (PCS), one of the leading organizations in the USA which estimates insured property/casualty losses. These indices cover the entire territory of the United States, individual regions (East, Northeast, Southeast, West and Midwest) and specifically those states with high catastrophe risk (Florida, Texas and California). Use of the new data pool has enabled not only improved geographic differentiation. Since the PCS indices cover between $70 \%$ and $85 \%$ of the US insurance market, they indicate the actual loss patterns more reliably than the earlier "underlying" indices. Thus transparency and credibility have been increased, and confidence in the alternative hedging instruments has been strengthened. Moreover, the period of the contracts has been lengthened from the original three months to a choice of either six or twelve months.

\footnotetext{
${ }^{3}$ This figure is calculated by Swiss Re's Product Management department. The loss reference corresponds to a natural catastrophe loss which is "rate but still possible at any time" and which, in the opinion of Swiss Re, insurance companies with average capitalization should take as a basis for deciding on the level of CatXL cover they require. For further explanation, see Sigma no. 6/1995, box on page 10 .

4 The capacity problem looks even worse if we consider the fact that only one fifth of the total property losses in question are insured. Thus the majority of the costs would presently fall upon the uninsured - or upon taxpayers.

5 See the boxed explanations in sigma no. 6/1995.

6 See CBOT (1995) and DURRER (1995).
} 
Trading in "PCS Cat Insurance Options" takes place mainly within the framework of so-called "call spreads" which are organised similarly to layers of traditional non-proportional reinsurance. This layered cover is achieved through a combination of two opposite positions: by simultaneously buying and selling call options with different strike values. The lower value represents the attachment point, whereas the upper value defines the exit point.

Figure 4: A simple hedging example using "PCS Call Spreads"

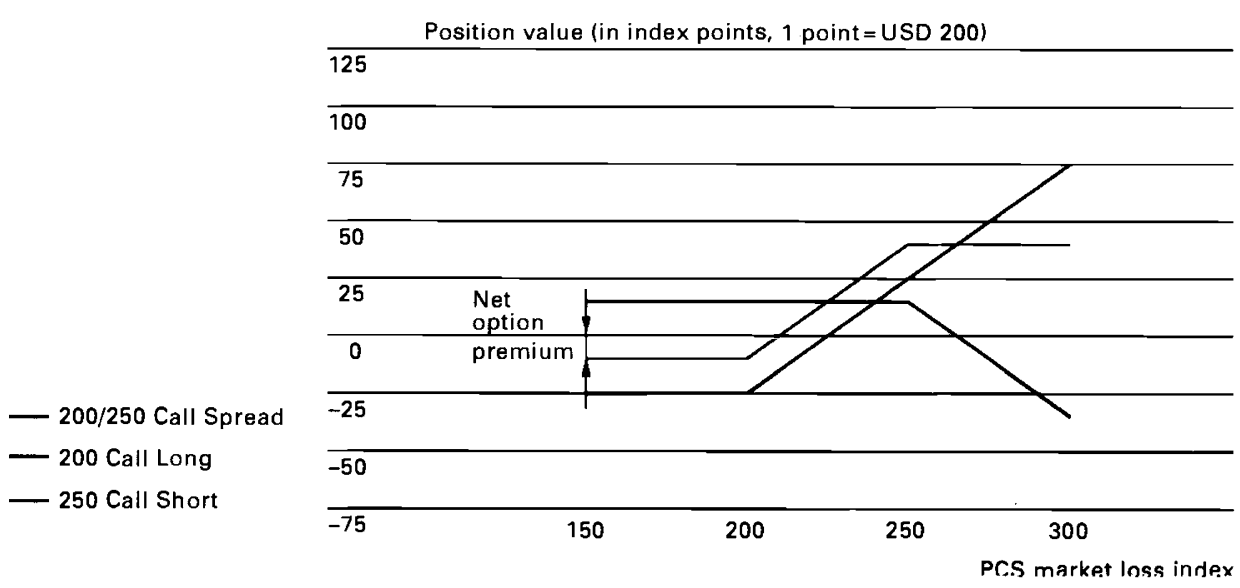

For example, imagine an insurance company which wants to reduce its earthquake risk exposure on the American West Coast. It thus buys a number (adequate for its portfolio) of "200/250 Western Annual Call Spreads". The buying of "200 call options", the first element of this double transaction, determines the priority of the cover: this begins as soon as the insured total loss in the Western region exceeds USD 20 billion (each index point represents an aggregated market loss of USD 100 million in the respective region). Through the simultaneous sale of " 250 call options", the acquired reinsurance protection is limited to the area of market losses between USD 20 billion and 25 billion. In this way, the insurer can tailor catastrophe cover more precisely to its needs and buy this cover at a lower net option premium.

According to definition, however, even after adjustments and improvements, the standardised contracts are still based on an average portfolio, whereas traditional reinsurance contracts relate to the individual original portfolios of the ceding companies. Due to this typical difference - in the so-called basis risk - the insurance derivatives of the CBOT cannot substitute custom-made reinsurance programs. Their potential relates to their usefulness as a flexible complement: in addition to filling in gaps in cover, they are suitable for the homogenisation of inadequately balanced risk exposures.

\subsection{The special exchange for catastrophe risks: "CATEX"}

An additional alternative concept for managing risk accumulation and the capacity problem in connection with natural catastrophes is currently being implemented in New York. A special exchange for catastrophe risks founded under the name "Catastrophe Risk Exchange" (CATEX) started to operate in October 1996. 
This latest exchange project aims to realise and simultaneously multilateralise a reciprocal risk transfer model. It enables licensed risk bearers - in addition to insurers, reinsurers and insurance brokers, mainly the market segment of large companies and their captives is also targeted - to exchange packages of specific catastrophe risks among each other on a regional basis and according to loss category. Transactions are processed via an electronic mailbox in which the relevant details of the risk units offered for exchange can be deposited - at first anonymously. At the opening of trading, the CATEX system provides a set of "benchmark exchange rates" which are based on historical loss distributions and the latest realised rates. Subsequently, these relative prices adjust to the current market forces within split seconds, until supply and demand are in balance. The insureds are not affected by this secondary risk transfer. Since no insurance policy portfolios are exchanged, but merely the respective cash flows, the claims handling is performed exclusively by those companies which have originally underwritten the individual risks. A suitable retention restriction ultimately ensures that no adverse selection takes place.

In contrast to the trading with insurance derivatives on the Chicago Board of Trade, there is no direct flow of additional capacity from the financial markets into the insurance industry via the CATEX exchange. However, an increase in the available total capacity occurs indirectly: through more efficient use of the available risk capital via improved diversification and especially through the inclusion of risk bearers who were hitherto isolated from the traditional insurance system (self-insurers via captives).

\subsection{Private placements via direct securitization}

Parallel to the alternative risk transfer activities that are underway on the CBOT exchange and planned for the CATEX exchange, several institutions including investment banks, reinsurers and direct insurers are currently developing models for securitization of catastrophe risks in order to place such risks directly with investors in the form of securities. The principle of securitization will now be illustrated using the example of a specially structured bond which will be issued in order to cover earthquake risks in California. ${ }^{7}$

The so-called "Earthquake Risk Bond" (ERB) is part of a state insurance program of the California Earthquake Authority (CEA) which should contribute towards solving the current capacity crisis in the market for earthquake cover in California. The project consists of multiple layers and involves the financial markets as well as the entire international insurance and reinsurance industries. Its realisation was tied to several conditions which have since been fulfilled. ${ }^{8}$ Nevertheless, the ERB issue, which is planned to take place in three series staggered over a year, still faces political hurdles at present since the definitive legislation process is delayed.

The ERBs have a 10-year maturity and a cash flow structure which targets the risk appetite of the appropriate investor group (see figure 5). Their semi-annual interest coupons promise a contingent yield which is clearly above the risk-free return on government bonds. If

7 The "Earthquake Risk Bond" of the CEA is used to explain the direct securitization model since it is the first publicly discussed and accordingly well-documented issue. Similar security structures are in development or are already being offered by various companies - including Swiss Re Financial Products.

${ }^{8}$ In addition to national tax exemption, these conditions involve mainly the broad participation of the private insurance industry ( $75 \%$ of the local homeowner's market) and corresponding cover commitments by reinsurers. 
an earthquake with losses exceeding USD 7 billion occurs in California during the risk period - i.e. within the first four years after the securities are issued - the interest coupons can be reduced to as little as $0 \%$ for the rest of the maturity period. In the extreme case of a natural catastrophe immediately following the subscription period, investors would receive a zero return. However, the repayment of principal at par value is fully guaranteed at final maturity, independent of the loss pattern.

Figure 5a: Earthquake risk bonds: cash flows to investors (without earthquake)

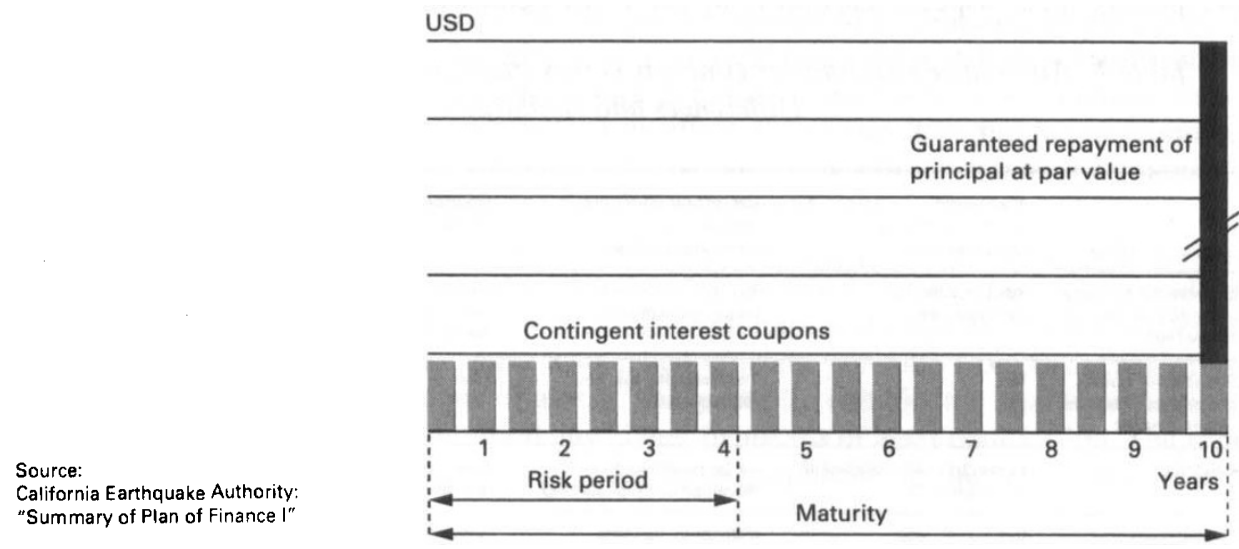

Figure $5 b$ : Earthquake risk bonds: cash flows to investors (if earthquake occurs) USD

Source:

California Earthquake Authority: "Summary of Plan of Finance I"

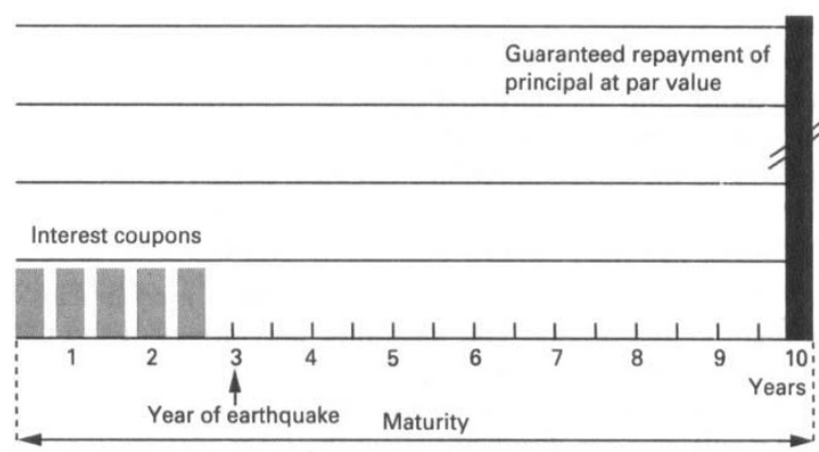

In order to raise the necessary capacity of USD 1.5 billion with this bond structure, an ERB volume of more than USD 3.5 billion must be issued. About 2 billion of this amount will flow into a fund consisting of government securities to ensure the repayment of principal at maturity; the remainder forms the actual risk capital for the fifth layer in the CEA 
program. Depending on the target investor segment, other securitization variations would also be promising: e.g. bonds with guaranteed (above-average) interest coupons which draw on the raised capital or - in return for even higher coupons - both elements at risk.

\section{Comparison from an insurance perspective}

Table 1 summarises the main similarities and differences between the alternative risk transfer concepts and traditional catastrophe reinsurance protection from an insurance perspective. (The aspects relevant to investors are dealt with in the next part.)

Table 1: Alternative risk transfer concepts versus traditional catastrophe reinsurance: Differences and similarities

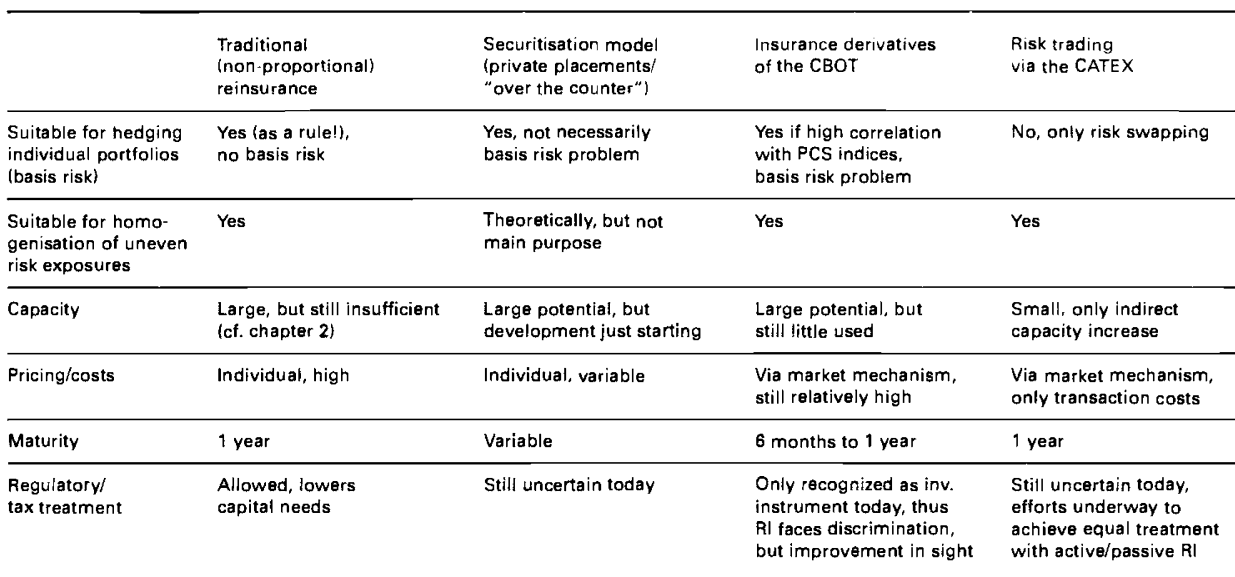

The main difference between customary CatXL covers and securitization solutions, on one hand, and standardised exchange contracts, on the other hand, lies in the so-called basis risk. Since the latter are based on aggregated loss indices, their suitability for hedging individual insurance portfolios depends decisively on their correlation with the representative average portfolio. Tailoring cover dimensions - in derivatives jargon : the determination of the hedge ratio - can be difficult in specific cases.

Moreover, the alternative risk transfer mechanisms are treated differently from a regulatory standpoint. The insurance derivatives of the CBOT are not (yet) recognised as reinsurance products, but merely as investment instruments. This hinders their use in view of the solvency requirements since the hedging effect does not flow into the technical result, and results in a tax disadvantage in the USA. Attempts are currently being made to improve this situation with the help of the National Association of Insurance Commissioners (NAIC). Via the same organisation and through influence on the authorities in individual states, CATEX is trying to achieve equal treatment of their risk-trading products with active and passive reinsurance. The regulatory and tax treatment of securitization solutions is still unclear at present. 


\section{The case for catastrophe risk as a new asset class}

Could insurance derivatives and securitized catastrophe risks someday evolve into a significant new asset class? What makes such engagements attractive from an investment perspective? Investors worldwide have always participated indirectly in catastrophe risk through (re-)insurance stocks. However, these shareholders carry somewhat willy nilly the asset-related risks as well as the liability-related risks of insurance companies, including those of their financial assets, whose volatility depends on macroeconomic developments and stock market performance. In comparison to this, investment vehicles whose returns are determined directly and solely by the loss pattern related to natural catastrophes offer a decisive advantage. In addition to an above-average yield potential with high volatility, their distinguishing feature is that their performance is not correlated with other financial risks. They thus promise an outstanding diversification effect. Due to similar - but not as pronounced - characteristics, investments in emerging markets have become an essential component of internationally diversified investment portfolios in recent years.

According to modern portfolio theory, investors generally prefer portfolios which exhibit the highest expected return at a given level of risk, or which display the lowest standard deviation for a specified average return. Through exploitation of the correlation features of different markets, investors thus select a so-called efficient portfolio from the range of all theoretically possible combinations of assets. This portfolio exhibits the characteristic that its risk-adjusted return cannot be raised any higher by means of asset reallocation. The sum of all the portfolios optimized in this way is displayed graphically as the "efficient frontier" (see figures 6).

The inclusion of insurance derivatives or securitized catastrophe risks to well diversified portfolios provides a text-book example with regards to applied portfolio theory. Using simulations in an optimization model, we have examined to what extent the risk-return tradeoff of nationally (US-wide) and globally diversified portfolios can be improved by the inclusion of investments whose return pattern depends on the pattern of catastrophe losses in the USA. ${ }^{9}$ The results of these modelling calculations are summarised in figures 6 .

These diagrams indicate the annualised standard deviation on the horizontal axis (from 1975 to 1995 and from 1985 to 1995 , respectively) and the corresponding average returns in US dollars on the vertical axis. The (volatility) risks and the (historical) returns of the individual asset classes are represented by the marked points. The curves connect all optimal riskreturn combinations which result from the correlation structure among the individual security classes.

The inclusion of catastrophe risks as a new investment alternative opens opportunities for even more efficient portfolio selection. The additional, almost completely uncorrelated diversification possibility shifts the so-called "efficient frontiers" upward, within both national and international modelling frameworks. This means that investors can achieve a portfolio mix with a lower risk for each level of expected return, and with a higher return for each level of risk.

9 These simulations modelled the investment alternative "catastrophe risks" on the basis of PCS data for the "National Index", applying an adaptive price mechanism. 
Figure 6a: "Efficient frontiers": US portfolio with and without cat risk

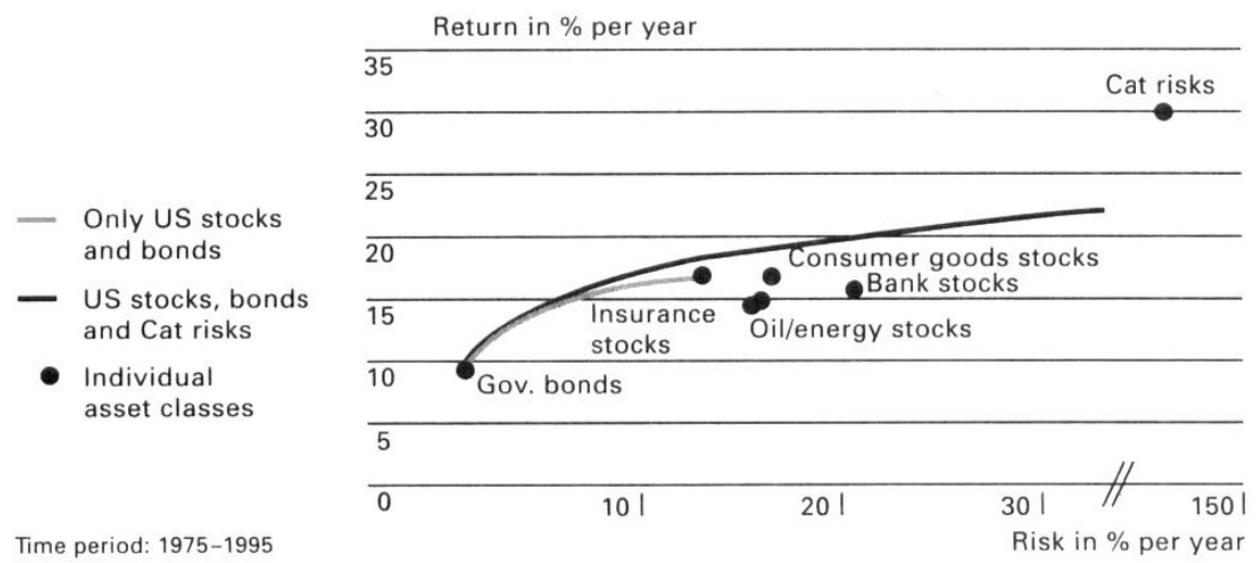

\section{Figure 6b: "Efficient frontiers": Global portfolio with and without cat risk}

- Only stocks and bonds

- Stocks, bonds and Cat risks

- Individual asset classes

- Major stock and bond indices of the US, J, UK, G, F, CH and CND financial markets

Time period: $1985-1995$, in USD

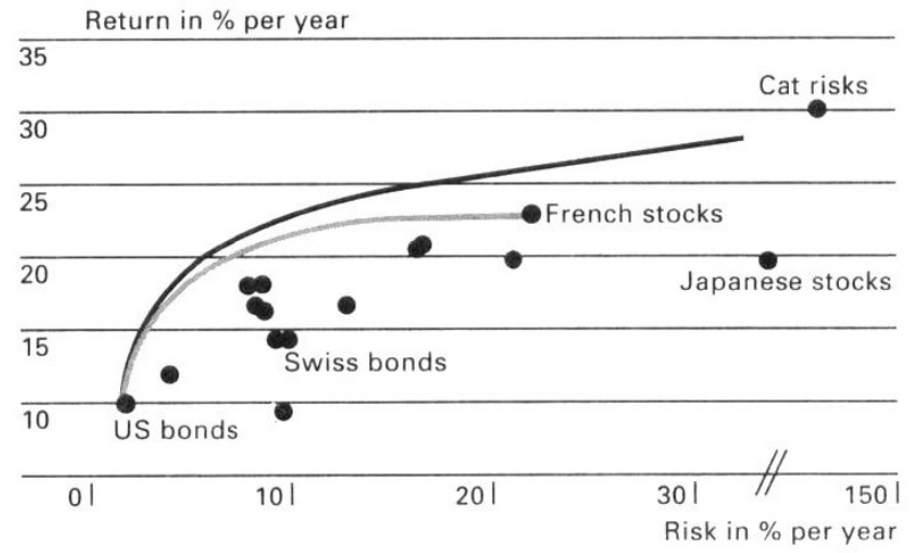

Figure 7 shows several optimal portfolio structures in a global context. For various target returns, we have used historical performance data from the world's largest stock exchanges and bond markets to provide the investment weights which minimize the resulting total risk. The structures displayed correspond to portfolios on the efficient frontier in the lower part of figures 6 . As expected, the optimal share of securitized catastrophe risks (or insurance derivatives) grows as target returns increase. In this process, asset classes which exhibit relatively low performance and volatility values - in terms of US dollars - are increasingly substituted. Portfolio risk rises disproportionately in relation to the increased return. However, in the chosen return range between $10 \%$ and $20 \%$, it rises more slowly than the portfolio share which is invested in catastrophe risks. 
Figure 7: Efficient portfolio structures: the optimal share of catastrophe risks grows as target returns increase

Portfolio return: $10 \%$ per year

Portfolio risk: $1.4 \%$ per year

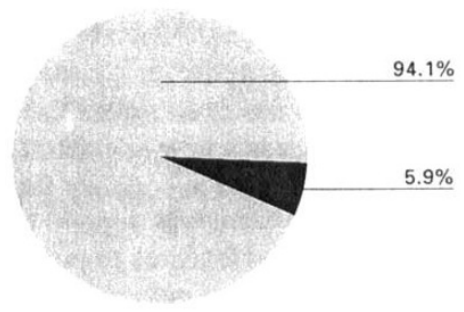

Portfolio return: $14 \%$ per year

Portfolio risk: $2.5 \%$ per year

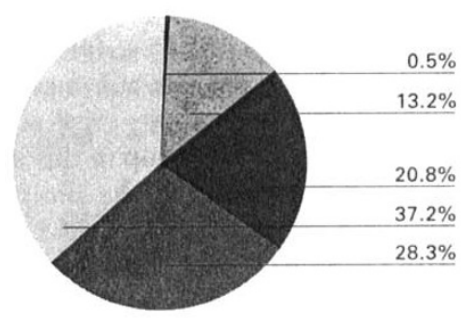

Portfolio return: $18 \%$ per year

Portfolio risk: $5.0 \%$ per year

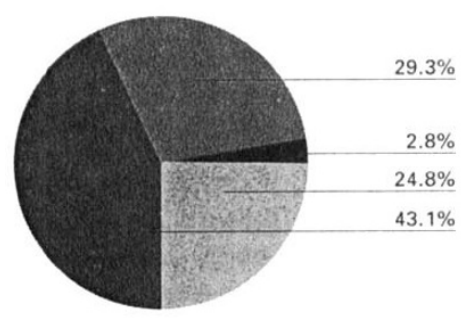

Portfolio return: $12 \%$ per year

Portfolio risk: $1.75 \%$ per year

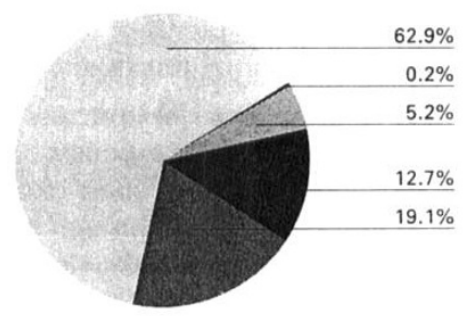

Portfolio return: $16 \%$ per year

Portfolio risk: $3.6 \%$ per year

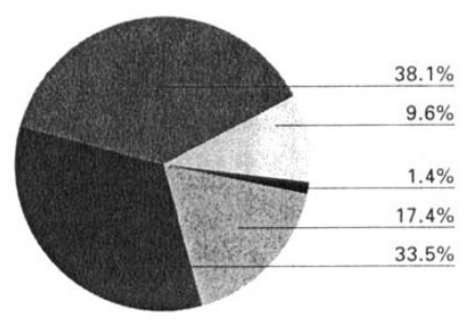

Portfolio return: $20 \%$ per year

Portfolio risk: $7.5 \%$ per year

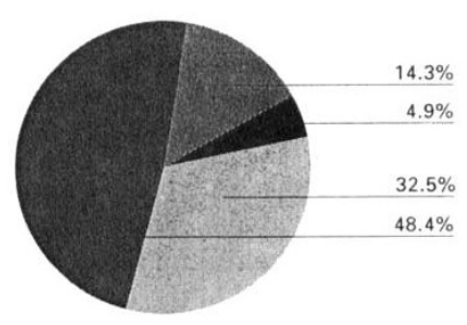

- US Cat risks

Asian assets

- European assets

US stocks

US bonds 
There is no doubt that an exaggerated engagement in insurance derivatives or securitized catastrophe risks would be very ill-advised - but so would the total neglect of these instruments. Despite their enormous volatility risk when viewed as isolated financial assets, they are better than nearly any alternative instrument for lowering portfolio volatility. This may run contrary to the intuition of cautious investors (which might be attributed to the latest, dramatically publicised "accidents" involving financial derivatives ${ }^{10}$ ). Yet the addition of the proper amount of investments in pure catastrophe insurance risks to a portfolio increases the potential return and simultaneously lowers the total risk.

Still largely unknown up to a short time ago, catastrophe risks which are securitized or in the form of derivative products could indeed establish themselves as a new and attractive asset class. Nevertheless, their excellent diversification qualities are of secondary importance where a swift breakthrough is concerned. Success in the short term will depend more on the ability to communicate clearly their advantages and operational features to potential investors (some of whom are presently still sceptical). In particular, the envisaged target group outside the insurance industry must be provided with a clear understanding of the pricing process.

\section{Outlook}

From both an insurance standpoint and an investment perspective, the long-term prospects look good for alternative means of transferring US catastrophe risks to the financial markets. On the demand side, our optimistic judgement is based on the capacity crisis recorded in the American storm and earthquake risk segment: A significant cover gap in this area within the traditional insurance system raises the fundamental question of the limits of insurability. On the supply side, the above-average performance prospects and impressive diversification features of the investment vehicles in question support a positive assessment. At the same time, the previously mentioned shortcomings stand in the way of a veritable "catastrophe euphoria" in a similar manner as the investor run on the emerging markets at the start of the 1990s.

Using simulation models, we have calculated the theoretically optimal weight of catastrophe risks in efficient investment portfolios for various target returns (see the pie charts in figure 7). Based on this information as well as the results of a broad survey of investment banks and potential investors in the USA, we anticipate an investment volume of between $0.5 \%$ and almost $1 \%$ of the US stock market capitalization. This corresponds to approximately USD 30 to 40 billion in additional capacity for the cover of US catastrophe risks.

However, this macroeconomically extrapolated level will not of course emerge overnight. A glance at the growth path of the trading volume in US Treasury Bond Futures, clearly the most successful financial innovation of the past decade, provides some indication of the time involved in the development cycle (see figure 8). Among the main catalysts for their breakthrough were diverse shifts in American fiscal and monetary policies which have

10 Often mentioned in this regard is the catastrophe which befell Britain's Barings Bank, which lost over USD 2 billion with Nikkei Index futures and options. But a general condemnation of derivative instruments based on such incidents is, in the words of Nobel Prize winner Merton Miller, comparable to a court decision which places the blame for drunken driving on the automobile instead of the driver! 
increased interest rate volatility. Similarly, the growth momentum of insurance derivatives and securitized catastrophe risks will not evolve independently from future catastrophe events and the general investment environment.

It is still difficult to estimate to what extent the alternative risk capital will flow from investors into the insurance industry via derivative exchanges as opposed to securitization. Following a head start for the first exchange contracts (already launched in 1992 on the CBOT), hedgers and investors can select from more and more vehicles today which are placed directly in the private market and traded "over the counter". Indeed, the upswing of most derivative intruments that are listed on major exchanges today began in this way.

Figure 8: For comparison: Trading volumes in US treasury bond futures

Trading volume

- Trend

Source: CBOT Market and Product Development

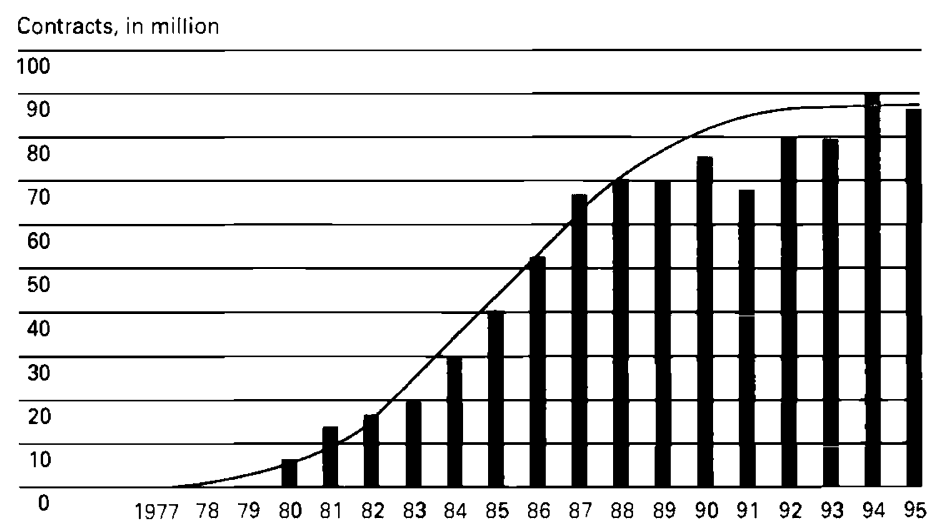

This experience suggests a development scenario for the alternative trading mechanisms of US catastrophe insurance risks such as outlined in figure 9. Over the long term, OTC transactions should be beneficial for exchange trading in standardised insurance

Figure 9: Development scenario for securitization and insurance derivatives

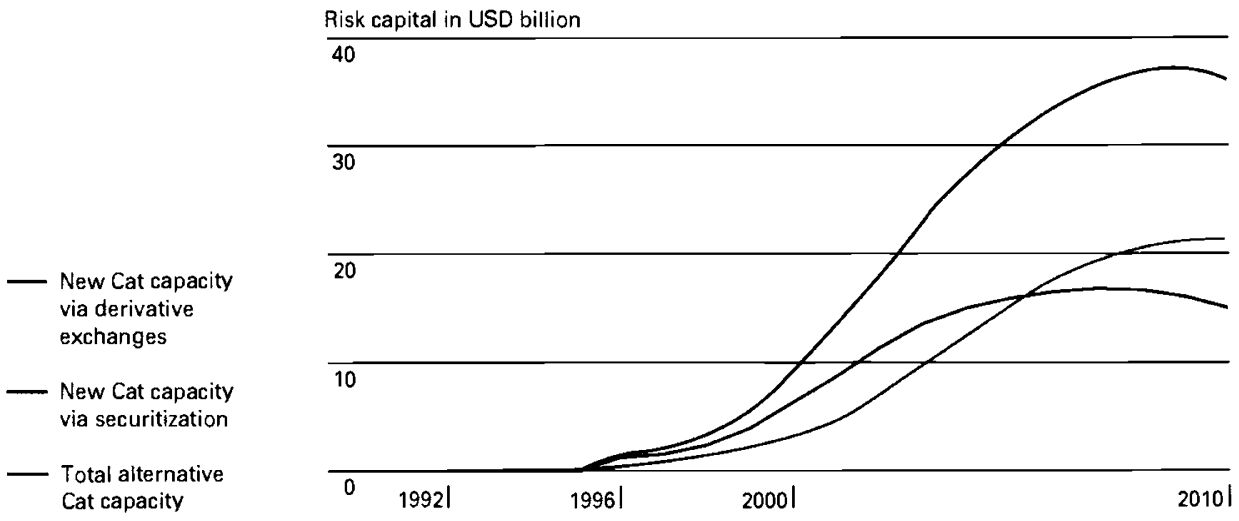


derivatives. To some extent, however, the alternative channels are also in direct competition since both are trying to attract the same investment capital.

The extrapolated value for the financial-market or supply side which should one day be available as additional reinsurance capacity for US catastrophe risks is roughly equivalent to the gap in cover registered in the traditional market (see part 2). If this substantial influx of alternative capacity flows exclusively as a complement into areas above layers underwritten today, no price pressure is expected in the traditional CatXL market. Such a scenario appears to be the most likely at present. Due to the basis risk problem, standardised exchange contracts are not capable of substituting custom-made reinsurance solutions. Solely as their flexible complement, they do not generate any direct price competition. And the most comprehensive securitization project to date is apparently aimed in the same direction: within the scope of the CEA program, only the fifth layer, which lies above the traditional insurance and reinsurance tranches, is targeted for direct placement in the financial market.

\section{REFERENCES}

California Earthquake Authority (CEA): Summary of Plan of Finance I - Issuance of Taxable Securities; prepared by Morgan Stanley \& Co. Incorporated/Bear, Stearns \& Co. Inc./Goldman, Sachs \& Co., New York, 1996.

Chicago Board of Trade (CBOT) : PCS Catastrophe Insurance Options - A User's Guide ; Chicago, 1995.

DURRER, Alex: Finanzderivate in der Assekuranz - Erfahrungen mit der Absicherung von Katastrophenrisiken ; in: Neue Zürcher Zeitung, no. 176, 1995.

DURRER, Alex, MARBACHER, Josef:The insurance industry in the context of finance and financial innovation: interrelations, parallels and perspectives; sigma no. 7, 1992; Swiss Re.

ELTON, Edwin J., GRUBER, Martin J.: Modern Portfolio Theory and Investment Analysis; Fifth Edition, New York, 1995.

ENZ, Rudolf, WEBER, Matthias, HESS, Thomas: Non-proportional reinsurance of losses due to natural disasters in 1995: prices down despite insufficient cover; sigma no. 6, 1995; Swiss Re.

ENZ, Rudolf, ZANETTI, Aurelia : Natural catastrophes and major losses in 1995 : decrease compared to previous year, but continually high level of losses since 1989; sigma no. 2, 1996; Swiss Re.

FROOT, Kenneth A. et al.: The Emerging Asset Class: Insurance Risk; Special Report from Guy Carpenter \& Company, Inc., New York, 1995.

HERI, Erwin W.: Die Emerging-Market-Euphorie; in: Finanzmarkt und Portfolio Management, no. 4, 1993.

McGHEE, Christopher M.: Insurance Derivatives: Solving the Catastrophe Problem ?; in:Viewpoint, no. IV, 1995.

MILLER, Merton H. : Finanzmarkt-Innovationen sind nicht an allem schuld - Eine nüchterne Analyse der jüngsten "Unfälle" mit derivativen Instrumenten; in : Neue Zürcher Zeitung, no. 46, 1996.

SHIMPI, Prakash: Insurance Futures - Examining the Context for Trading Insurance Risk (unpublished speech manuscript); New York, 1995.

TILLEY, James A.: The Latest in Financial Engineering: Structuring Catrastrophe Reinsurance as a High-Yield Bond; Memorandum from Morgan Stanley \& Co. Incorporated, New York, 1995. 